\title{
CIELOS! ('Holy Cow')
}

keywords: animales de producción; vacas; bienestar animal; Derecho Animal

Cielos!, otra vez con la carne roja, las hamburguesas y los embutidos!.

Esta es la expresión, con los ojos en blanco y las cejas levantadas, que deben de haber empleado muchos de los que, estas semanas atrás, han leído al menos las noticias relacionadas con el informe de la OMS, advirtiendo del potencial riesgo de sufrir cáncer colorectal, de próstata y de páncreas por exceso en el consumo de carnes rojas y procesadas[1].

Cielos!; Dios mío!, es la traducción que le doy a esa expresión coloquial muy usada en Inglaterra antes de la I Guerra Mundial y popularizada por el lenguaje de los cómics americanos: " "Holy Cow, Batman", le dice Robin a su jefe. No es fácil encontrar una buena traducción a las expresiones coloquiales, porque se usan dentro de un contexto de entendimiento previo entre los que la usan, pertenecen a ese apartado de un lenguaje que tiene que ver con la figuración, la sinrazón -que suele ser bastante abultado-, y que, sin embargo, es el nervio de un idioma.

Hace poco tropecé, literalmente, sí!, con un libro que no iba buscando en una librería especializada en libros en inglés. El título "HOLY COW"[2], nada tiene que ver con las "vacas sagradas" de la India, aunque parece que el origen remoto de la expresión en inglés: "Holy Cow!", sí tiene también connotaciones con el respeto debido a estos animales por el hinduismo. Pero, connotaciones de origen aparte, lo cierto es que el libro terminó en mis manos y no lo dejé hasta que leí la última línea. 


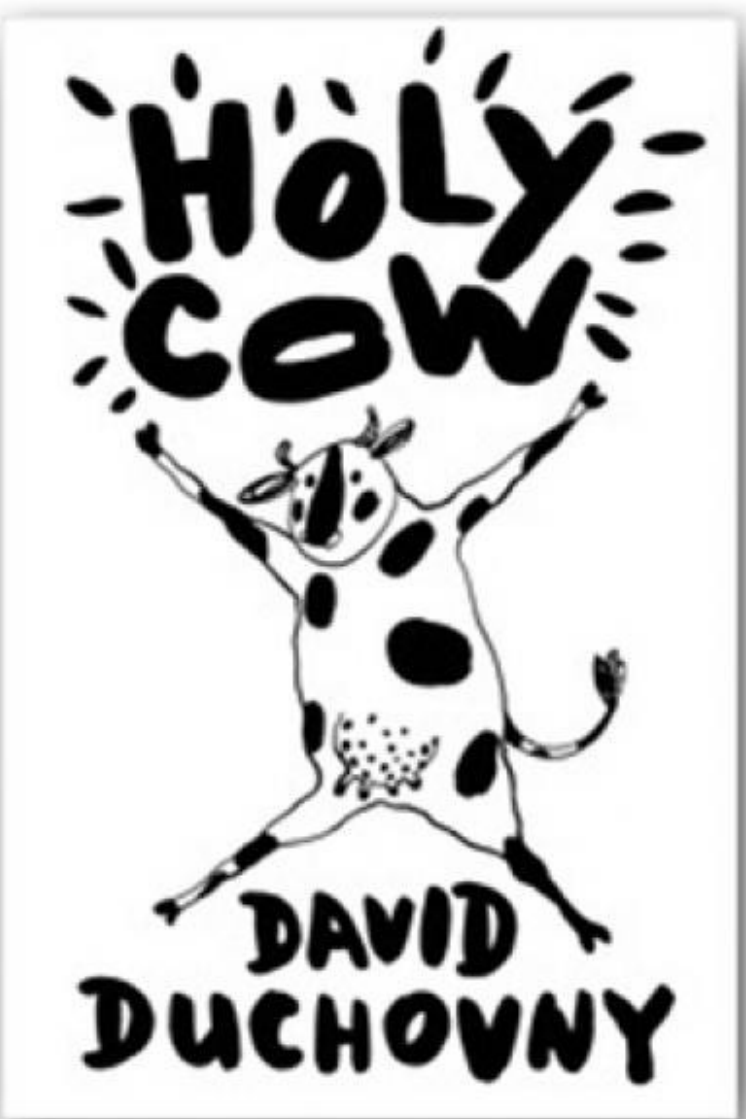

Vale la pena leerlo. Describe en primera persona la vida de una vaca feliz, Elsie Bovary (un guiño a Flaubert), cuya vida se transforma por la impresión que recibe ("Holy Cow!!!) al observar, a través de una ventana de la granja donde vive plácidamente y ha vivido así toda su familia -aunque no consigue explicarse por qué un día desapareció su madre-, que las pequeñas granjas, como la que ella comparte con su amiga Mallory, los cerdos, los pavos y las gallinas, van a desaparecer y que lo que va sustituir a esas amables granjas serán los establecimientos de carne industrial ("industrial meat farm"). Elsie Bovary empieza a ver en una pantalla, a las gallinas hacinadas en cajas amontonadas en hileras de más de cinco alturas, a los cerdos apretados unos contra otros en hangares y a las vacas, como ella, que mueren en medio de ríos de sangre. Su sorpresa al despertar a esa dura realidad, le hace descubrir el término "carne" y piensa que los humanos son capaces de comer lo que sea, con sólo ponerle un poco de sal y mantequilla.

Elsie Bovary, ella misma lo dice, no está dispuesta a vivir ni un minuto más en espera de verse degollada y convertida en pedazos que se servirán en la mesa. Desde el principio del relato, manifiesta su falta de entendimiento de por qué los humanos beben la leche de las vacas, cuando ellas no se acercan a la dueña de la granja cuando amamanta a su bebé para preguntarle: "Oiga, me deja probar un poco de su leche?". Así que -y no voy a contar nada más de la trama-, decide fugarse de la granja con dos de sus mejores amigos: Shalom, un cerdo gruñón y Tom, un pavo sofisticado (según él mismo afirma) que no puede volar pero puede usar un iPhone con el pico.

El libro está escrito con humor, pero no es una mera sátira, sino que el autor dirige una mirada llena de inteligencia, de comprensión y de complicidad a la vida de los animales, a los que hace hablar con naturalidad y desparpajo. El autor, de sobra conocido por su faceta de actor, se revela como un defensor de los animales de granja, que clasificamos como "de producción", lo que revela la misión del término, que no es otra que esconder la realidad de la industria cárnica, que no está destinada a ofrecer una vida idílica a los animales, sino a abastecer los supermercados.

En efecto, el informe de la OMS ha levantado ampollas y es una realidad innegable que va a seguir provocando reacciones en contra. Pero, como decía uno de los autores del mismo[3], lo que tiene que hacer la gente es decidir a quien cree: a los industriales o a los científicos. El consumo de carne es excesivo en todo el mundo y produce enfermedades. Esto es un realidad constatable. Dejar de consumir 
carne y adoptar una dieta vegetariana o vegana es más que una opción personal, ética (que lo es), es, además, una muestra de coherencia y de respeto por los animales con los que compartimos este mundo, aunque no nos crucemos con ellos ni convivamos como lo hacemos con los perros o los gatos.

La regulación europea de los animales de producción, desde hace 40 años, trata de asegurar unos estándares de bienestar que respeten su idiosincrasia, sus necesidades y sus intereses. En concreto, en relación con los animales de granja, la primera regulación europea se remonta a 1974, en la que una Directiva europea regula el sacrificio de animales en el matadero. Pero no es hasta 1999, con el Tratado de Amsterdam cuando se regula, en un protocolo anexo al mismo[4], el tratamiento de los animales como seres sintientes ("sentient beings") en el estabulamiento, transporte y sacrificio de los mismos. Espíritu que recoge el TFUE de Lisboa en su art. 13. Una pieza central de la legislación europea de bienestar animal, es la Directiva 98/58/CE de 20 de Julio de 1998, sobre la protección de los animales en las explotaciones ganaderas, que establece los mínimos estándares durante la permanencia de los animales en las granjas, mientras que otras directivas se refieren al bienestar de los animales durante el transporte y el sacrificio.

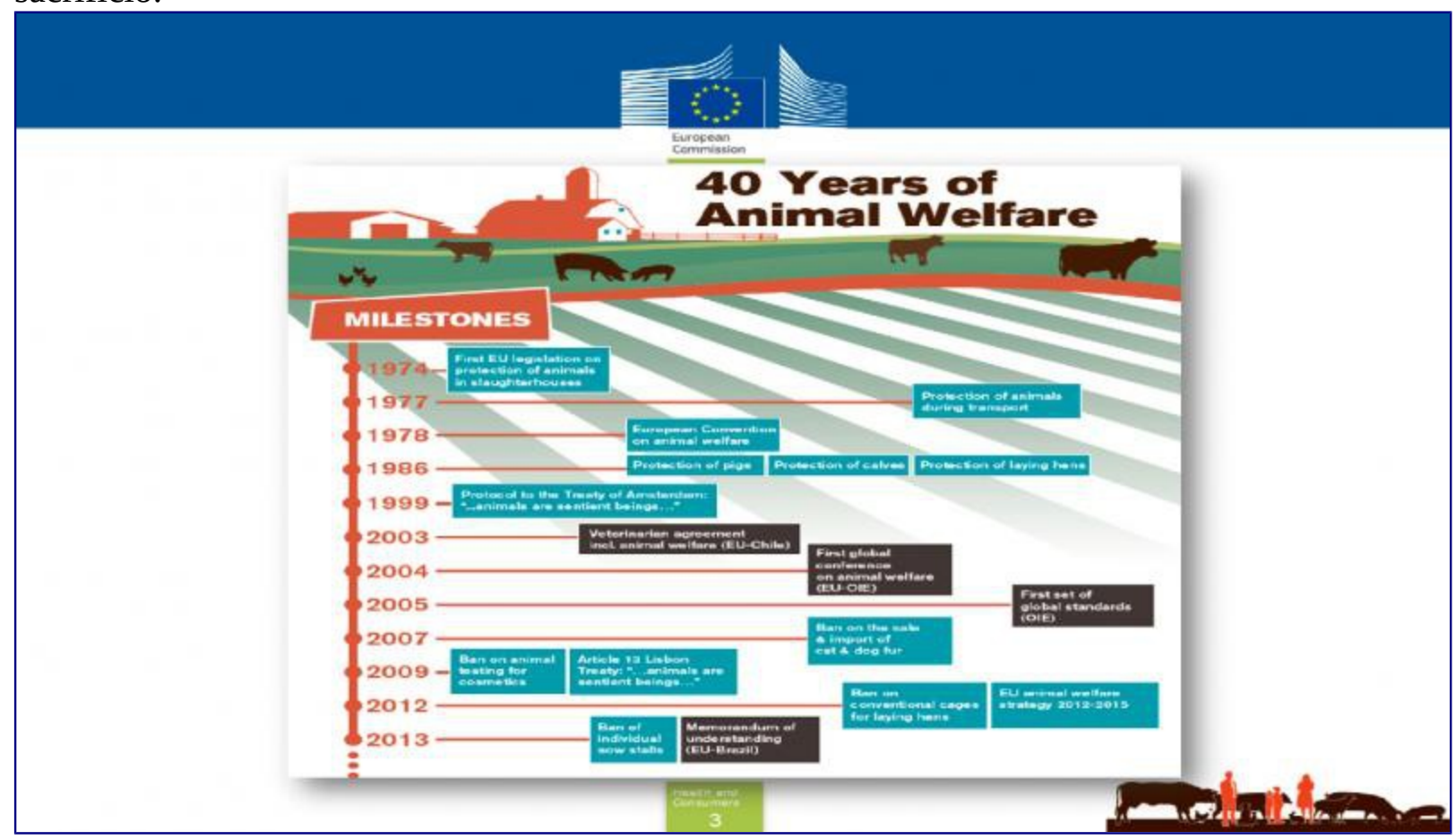

Clica para ampliar

En España, la ley 32/2007 de 7 de Noviembre para el cuidado de los animales en su explotación, transporte, experimentación y sacrificio, es el único instrumento legislativo de protección animal, de ámbito general. Se echa en falta, desde hace años una ley general de protección animal en España, que termine con la maraña legislativa, que tan difícil hace la consulta de normas relativas a los animales y, con ello, la mejora de su protección.

La legislación es un instrumento de ordenación de una realidad, en nuestro caso, de las producciones ganaderas. Pero no basta con la existencia de la misma, conviene difundirla (muchos de nuestros conciudadanos la desconocen), conviene formar expertos en la aplicación de dicha legislación y conviene crear una conciencia social, a través de la Educación a todos los niveles, que nos haga considerar también a las vacas como animales que sienten, no sólo como agentes productores de la leche en botella o brik.

David Duchovny, en el libro que motiva este editorial, señala el camino hacia un entendimiento mutuo y una aceptación de las necesidades de los animales que el mundo necesita desesperadamente. 
Universitat Autònoma de Barcelona Sígueme en Facebook: https://www.facebook.com/editora.da

[1] Sobre las carnes rojas y procesadas, vid, en detalle, OMS.

[2] DUCHOVNY, David, Holy Cow (London 2015).

[3] Kurt Straif, Jefe del Programa de Monografías del IARC (International Agency for Research of Cancer), órgano de la OMS

[4] Treaty of Amsterdam amending the Treaty on European Union, the Treaties establishing the European Commun ties and related acts.

Protocol on Protection and Welfare of Animals annexed to the Treaty of the European Community. Official Journal, C. 340, 10.11.1997. 